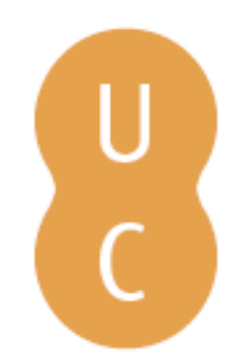

\title{
nommalina
}

\section{Preparação e confecção dos alimentos e utensílios de cozinha nos fragmentos de} Arquéstrato de Gela

\author{
Author(s: $\quad$ Cação, Elisabete \\ Published by: Imprensa da Universidade de Coimbra \\ Persistent URL: URI:http://hdl.handle.net/10316.2/29980 \\ DOI: $\quad$ DOI:http://dx.doi.org/10.14195/978-989-721-008-2_4
}

Accessed : $\quad$ 23-Dec-2017 10:26:16

The browsing of UC Digitalis, UC Pombalina and UC Impactum and the consultation and download of titles contained in them presumes full and unreserved acceptance of the Terms and Conditions of Use, available at https://digitalis.uc.pt/en/terms_and_conditions.

As laid out in the Terms and Conditions of Use, the download of restricted-access titles requires a valid licence, and the document(s) should be accessed from the IP address of the licence-holding institution.

Downloads are for personal use only. The use of downloaded titles for any another purpose, such as commercial, requires authorization from the author or publisher of the work.

As all the works of UC Digitalis are protected by Copyright and Related Rights, and other applicable legislation, any copying, total or partial, of this document, where this is legally permitted, must contain or be accompanied by a notice to this effect. 


\section{Contributos para a história da alimentação na antiguidade}

Carmen Soares, Paula Barata Dias (coords.) 


\title{
Preparação e confecção dos alimentos e utensíllos de cozinha nos fragmentos de Arquéstrato de Gela
}

\author{
Elisabete Cação \\ Universidade de Coimbra
}

Neste trabalho propomos a análise dos fragmentos de Arquéstrato, delimitando o nosso estudo primeiro aos métodos de preparação, depois à confecção dos alimentos e, por fim, aos utensílios necessários à confecção.

Situamos a obra de Arquéstrato entre o final do século IV e o século III a. C. O poema, composto em verso épico, Hedypatheia, estaria perdido não fossem as valiosas citações de Ateneu de Náucrates, num total de mais de sessenta fragmentos, na obra Sábios à Mesa ou, na forma transliterada, Deipnosofistas. Para a citação dos fragmentos usamos a edição de Olsen-Sens, publicada pela Oxford.

\section{Preparação dos alimentos}

Nesta rubrica, consideramos as referências feitas ao tratamento dado aos alimentos antes de sujeitos ao fogo. Fazemos agora um levantamento daquilo que consideramos mais importante em Arquéstrato.

a) Esmagar/ Triturar (de tribô): esta acção aparece nos fragmentos 11.9 e 23.5 na forma de partícipio aoristo do verbo (tripsas), método aplicado ao esmagar de ervas aromáticas (euodê anthê) que, supomos, poderiam ser esmagadas num tradicional almofariz ${ }^{1}$.

b) Golpear o peixe (de kenteo): no fragmento 32.5, ao descrever a melhor maneira de confeccionar peixe-cítara (kitharon), o autor antigo aconselha uma forma simples para uma qualidade de peixe, que supomos melhor, e outra para um de qualidade inferior: para este último, um mais pequeno e ruivo, aconselha que se golpeie kentesanta o peixe ${ }^{2}$.

c) Partir às postas (de temnô): era também possível fazer cortes simples, como os que aconselha para a preparação de bifes de atum, nos fragmentos 38.3 e 39.2.

d) Untar (de aleiphô). É um método de preparação referido de duas formas: a mais corrente, usando o azeite, é uma expressão primeiramente usada para designar o acto de cobrir o corpo com azeite, como faziam os atletas. Nos fragmentos 37.8 e 38.4 a expressão direcciona-se para cobrir o

\footnotetext{
${ }^{1}$ Vide Sparkes 1962: plate VIII.3 e plate IV.4.

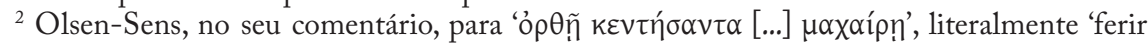
com uma faca a direito', ensaia a seguinte tradução 'poking holes', explicando a realização destas cavidades no peixe pela verticalidade que lhe sugere orthê.
} 
corpo do alimento apenas com azeite, mas no fragmento 32.6 usa-se também para designar o método de untar com queijo, ainda que haja um verbo próprio para aplicar queijo nos alimentos: tureuô ou turố. No fragmento 46.13, a propósito do excesso de temperos, Arquéstrato desaconselha a aplicação excessiva de queijo nos alimentos de boa qualidade, uma vez que isso arruinaria (diaphtheirousi) todo o preparado. Contudo adverte que nem sempre o uso de queijo é prejudicial ao tempero dos alimentos, mas este caso é o exemplo-regra da sua utilização excessiva.

e) Entrouxar: envolver em folhas de figueira e atar com um fio fazendo

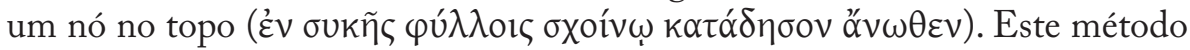
é usado no fragmento 36.8 para descrever a preparação do bonito. Parece-me extremamente curioso anotar a modernidade do uso de um fio, assim como hoje em dia se fariam os tradicionais rolos de carne ou as trouxas.

\section{Confecção dos alimentos}

Ao analisar os fragmentos de Arquéstrato, pudemos observar que os verbos hepsô e optaô são os mais utilizados para indicar o processo de cozedura dos alimentos 3 . Enquanto hepsô se usa com o sentido de 'cozer em água' ou 'ferver', optao emprega-se para designar 'assar' ou 'grelhar'. No entanto, quando a acção deste último é realizada numa frigideira ( $\tau$ ŕyovov) é mais correcto traduzir-se por 'fritar'.

A estes processos usuais de confeccionar, acrescentamos um outro,

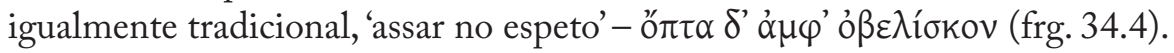

A preposição amphi com acusativo significa 'à volta de'. Ou seja, esta preposição contribui para a melhor compreensão do uso de um obeliskos, utilizado, como sucede ainda hoje em dia, para assar os alimentos, fazendo incidir o calor sobre todos os lados, à medida que se vai rodando o espeto. Arquéstrato recorre ao mesmo método de confecção, já não para o peixe aulopias como o exemplo dado aqui, mas para uma peça de caça, a lebre, no fragmento 57.

A todos estes processos de cozinhar subjaziam os riscos de arruinar o prato por excesso de calor, aquilo que vulgarmente se designa por 'queimar' ou, em linguagem popular, "bispar" o cozinhado. Nesse sentido, são naturais os vários conselhos de Arquéstrato para os evitar.

Ao referir os braseiros ${ }^{4}$ para cozinhar alimentos, Arquéstrato evidencia no

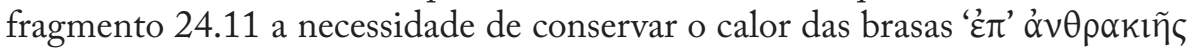

\footnotetext{
${ }^{3}$ Nos fragmentos analisados contabilizámos um total de cinco referências para hepsô e doze para optấ. hepsô - frgs. 19, 23, 32, 50, 60; e optâे - frgs. 11 (tr. fritar), 13, 14, 23, 24, 32, 34, $36,37,38,46,57$.

${ }^{4}$ Sparkes 1962: plate V.3.
} 
$\varphi \lambda$ ó$_{\alpha^{\prime}}$ ', literalmente 'manter o fogo aceso' ou, como sucede no fragmento 36.910, de manter as cinzas quentes 'spodos thermen' (36.9) tendo o especial cuidado de as atiçar, mexendo-as de fora para dentro (esô), de forma a manter as brasas vivas. Pois se se queimavam os alimentos, o inverso também acontecia: isto é, também ficavam mal assados. Aliás, nos achados arqueológicos ${ }^{6}$ conseguem notar-se áreas mais queimadas ou mais escurecidas pelo fogo nos utensílios de cozinha, mas obviamente isso decorrerá sobretudo do seu uso diário. No entanto, Arquéstrato argumenta, no fragmento 57.4, que a melhor forma de servir lebre (lagôs) será mesmo um pouco mal passada (mikron enomoteron).

Ainda acerca da possibilidade de queimar os alimentos cozinhados, em dois outros fragmentos 23.4 e 24.12 , Arquéstrato recomenda que se mexa sempre bem os preparados: no primeiro 'thama' (muitas vezes) e no segundo fragmento 'pukinôs' (frequentemente ou energicamente). Sparkes (1962), no seu artigo sobre cozinha grega, mostra-nos vestígios inclusivamente do utensílio de que se serviriam os gregos para esse fim: uma concha de terracota ${ }^{7}$.

A propósito dos processos de condimentação dos alimentos durante a sua cozedura, no fragmento 24, o autor de Hedypatheia demora-se a descrever como cozinhar e, posteriormente, condimentar cação. Cada parte deste peixe deverá ser confeccionada diferentemente, consoante seja a barriga (bypogastria) ou o restante corpo. Ainda que a barriga do cação deva ser temperada antes, às outras partes (koilês), passíveis de cozinhar, não se deve proceder a qualquer tipo de mistura ou adição de tempero mais forte que o azeite, bem como condimentar com cominhos e ervas aromáticas no final da cozedura:

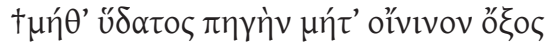

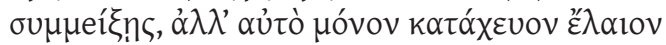

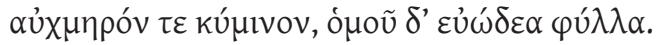

Há ainda um outro modo de explicitar a aplicação de molhos e ervas aromáticas nos alimentos: salpicar e regar (de passô e rhainô). Atesta-se no fragmento 38.4 o uso do particípio aoristo pasas (salpicar), e no fragmento 46.14 o do particípio presente rhainontes (regar).

Uma outra forma de confecção é também os ensopados. Arquéstrato no fragmento 23.6 usa duas expressões semelhantes para o significar: ensopar e mergulhar (de diiêmi e embaptô), as duas acerca da confecção da cabeça de peixe-porco.

\footnotetext{
${ }^{5}$ Ibidem: plate VIII.4.

${ }^{6}$ Cubberley 2003, passim.

${ }^{7}$ Sparkes 1962: plate VII.1.
} 


\section{Utensílios de cozinha}

Ainda que tenhamos noção de que a poesia de Arquéstrato é dedicada aos prazeres gastronómicos da cozinha regional mediterrânica, sobretudo dirigida a uma elite, não podemos deixar de fazer a ressalva de que, conforme sugerem Wilkins e Hill ${ }^{8}$, todos os utensílios aludidos eram de uso quotidiano e não objectos de luxo.

Podemos afirmar que Arquéstrato refere os mais conhecidos e utilizados, dos quais se conversam vestígios arqueológicos espalhados pelos mais importantes museus na Europa (exemplos de que nos temos servido para ilustrar a nossa apresentação).

Além dos já anteriormente referidos, espeto e braseiro, recuperamos a alusão ao teganon ${ }^{9}$ que, como dissemos antes a propósito do processo de fritura, se assemelha a uma frigideira. Este utensílio é referido nos fragmentos 11.8 e 61.2. O fragmento 61 é particularmente esclarecedor sobre a sua utilização para fritar, isto é, fazer ferver o azeite. Nesse passo, Ateneu cita ${ }^{10}$ a obra de provérbios de Clearco, um filósofo Peripatético, em cujo fragmento se explica que, uma vez o teganon quente, se colocaria o peixe miúdo (aphuê) a fritar, e

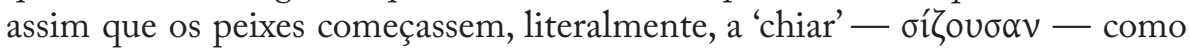
acontece com o azeite (kathaper toulaion), deveriam ser retirados.

Quanto ao utensílio designado por lopas ${ }^{11}$, ainda que tenham, obviamente, uma aparência distinta, Sparkes ${ }^{12}$ argumenta que todas são representações de lopades: a do meio mais rasa; e as das pontas são semelhantes às chutrai, de que Arquéstrato não fala, mas que poderíamos associar a panelas, em geral. Estas lopades seriam exemplos de ou onde se serviriam os pratos já prontos (o exemplo mais raso de lopas, equivalente às modernas travessas), ou pequenas caçarolas com orifícios que iriam ao lume para que, depois de colocadas nos braseiros, pudessem facilmente libertar o vapor.

Para os típicos fornos portáteis, o autor utiliza termos distintos que corresponderiam a objectos diversos ${ }^{13}$.

O ipnos ${ }^{14}$, em 47.4, é um exemplo disso: um forno assente em quatro pernas que estava bastante difundido tanto entre Gregos como Romanos.

${ }^{8}$ Sobre esta questão, vide Wilkins e Hill 2006: 74-78.

${ }^{9}$ Sparkes 1962: plate V.5.

${ }^{10}$ Ateneu 7.23.1 (G. Keibel, Leipzig, 1966).

${ }^{11}$ Sparkes 1962: plate VI.3.

12 Ibidem: 130 e sqq.

${ }^{13}$ Quanto à noção de espaço de cozinha na Grécia, os autores são unânimes em relação à sua inexistência. Por isso, os fornos e braseiros seriam de dimensões reduzidas para que fossem facilmente transportáveis. Vide Sparkes 1962: 127; Dalby 2003a: 188; Wilkins e Hill 2006: 64-67.

${ }^{14}$ Sparkes 1962: plate V.1. 
Deixei, precisamente, o klibanos para o fim, pois este mereceu de Cubberley (1988) um artigo especial, no qual o autor propõe uma redefinição de alguns vestígios arqueológicos classificados como outros utensílios e que deveriam pertencer à família dos baking covers, como the chama.

Sparkes $^{15}$ (1962) considera o pnigeus grego ${ }^{16}$, que não encontramos em nenhum fragmento de Arquéstrato, o mesmo que o testum latino e define o uso destes utensílios exactamente como Cubberley (2003) redefinirá mais tarde o klibanos grego ou o sub testum latino.

Klibanos $^{17}$ ainda é o termo, antes de mais pela sua tradução, que levanta mais dificuldade quer pelas suas características, quer pelo modo de uso, e por consequência pela sua fraca identificação nos vestígios arqueológicos da Antiguidade. Mas quanto a este termo, tomaremos em conta a hipótese fundamentada de Cubberley ${ }^{18}$ que assevera a necessidade de redefinição de alguns vestígios de utensílios de cozinha. Isto é, o utensílio a que chamamos klibanos, e que normalmente era usado para cozer pão, poderá ter sido utilizado para a confecção de outro tipo de alimentos, nomeadamente assar carnes, ou posteriormente como queimadores de incenso e outros perfumes ${ }^{19}$.

Aliás, este último autor admite que prigeus e klibanos são o mesmo utensílio ${ }^{20}$. Cubberley considera ainda que a palavra grega klibanos, transcrita em latim clibanus, será apenas um estrangeirismo usado para referir um utensílio comum entre os romanos. Na verdade, sub testum quer apenas dizer 'por baixo da tampa' ou 'por baixo do recipiente', como se faria com os klibanoi. Para usar este utensílio, era feito um buraco na terra, na qual se depositariam brasas vivas ou cinzas quentes que aqueceriam o klibanos, e onde, depois de removida a fonte de calor, se depositariam os alimentos a ser cozinhados, possivelmente em cima de folhas.

Cubberley acredita que muitos vestígios arqueológicos poderão estar mal classificados, pois os klibanoi, se virados para cima, assemelham-se a uma qualquer taça, situação que se agrava quando as suas características pegas ou asas estão irremediavelmente perdidas, impossibilitando uma correcta classificação do objecto. No seu estudo de 1988: 107-8, o estudioso reclassifica uma série de artefactos que considera vestígios de klibanoi e caracteriza exaustivamente os vários tipos.

\footnotetext{
${ }^{15}$ Sparkes 1962: 128.

${ }_{16}$ Sparkes 1962: plate IV.2.

${ }^{17}$ Cubberley in Dalby 2003: 57, 59, 61 e 65.

${ }^{18}$ Cubberley et alii 1988: especialmente 99-100.

${ }^{19}$ Ibidem: 101. Cubberley, para desenvolver a teoria de que o clibanus servia efetivamente para outros tipos de confecção, apoia-se em autores antigos como Apício $(7.5,5 ; 7.8)$. O autor serve-se ainda de Pseudo-Ambrósio em Act. Seb. 16.58 para justificar esta valência do clibanus.

${ }^{20}$ Cubberley 1988: 100.
} 
Resumindo o seu estudo, os klibanoi podem apresentar vários tamanhos, entre 24 a $50 \mathrm{~cm}$ de diâmetro, sendo que os maiores são datados do início do Império Romano. Os exemplares mais antigos têm uma cúpula redonda e os mais recentes, possivelmente do IV e $\mathrm{V}$ séculos d. C., têm uma cúpula achatada. Os vestígios de klibanoi, que chegaram até nós, permitem-nos ainda afirmar que eram decorados, como os vasos gregos.

Depois desta análise, podemos falar da modernidade da cozinha grega e romana. Se consideramos estes utensílios algo rudimentares, já as técnicas dos métodos de confecção não se afastam muito dos próprios e tradicionais pratos da cozinha mediterrânica: os grelhados, assados e estufados.

Temos ainda de considerar o contexto de luxo da matéria poética e o facto de Arquéstrato escrever para uma elite e não para as massas. Podemos supor que os preparados apresentados pelo autor antigo fossem os habituais, por exemplo, num contexto de symposion. 


\section{BibLIOGRAFIA}

A. L. Cubberley (2003) «Bread-baking in Ancient Italy. Clibanus and Sub Testu in the roman world: further thoughts», in Dalby, Food in Antiquity, University of Exeter Press, pp. 55-68.

A. L., Cubberley, J. A. Lloyd, P. C. Roberts (1988), «Testa and clinabi: The baking covers of Classical Italy», Papers of British School at Rome, vol. 56, pp. 98-119.

A. Dalby (2003), "Archestratos. Where and when?», in Dalby, Food in Antiquity, University of Exeter Press, pp. 400-412. (2003a), Food in the Ancient World. From A to Z (London and New York).

S. D. Olsen (2000), A., Archestratus of Gela, Greek Culture and Cuisine in the Fourth Century BCE, Text, translation, and commentary, Oxford University Press.

C. Soares (2012), «Receitas do mais antigo Guia Gastronómico: Iguarias do Mundo de Arquéstrato», in Candido, Maria Regina (org.), Práticas Alimentares no Mediterrâneo Antigo, Rio de Janeiro, NEA/ UERJ, pp. 33-59.

B. A. Sparkes (1962), «The Greek Kitchen», Journal of Hellenic Studies, vol. 82, pp. 121-137.

J. Wilkins, S. Hill (2011), Archestratus: the life of luxury, Prospect Books (2006), Food in the Ancient World, Blackwell.

\section{http://latis.exeter.ac.uk/classics/undergraduate/food3/archestratus.htm}

(De Junho de 1999. Criado por Fiona McHardy. Consultado a 09/ Outubro/2011) 